ARTICLE REVIEW

\title{
Six Sigma Practices Integrated with IR 4.0 for Sustainability in Malaysian Healthcare Industry
}

\author{
Diekola Akanmu* and Norshahrizan Nordin \\ Faculty of Applied and Human Sciences, Universiti Malaysia Perlis 01000, Kangar, Perlis, Malaysia. \\ *For reprint and all correspondence: Muslim Diekola Akanmu, Faculty of Applied and Human Sciences \\ Universiti Malaysia Perlis 01000, Kangar, Perlis, Malaysia.
}

Email: diekola@unimap.edu.my

\begin{abstract}
Provision of safe, reliable, and affordable care while improving performance and efficiency remains a challenge in the healthcare sector. This study, therefore, reviews the previous researches on the effect of six sigma and industrial revolution 4.0 technologies (IR 4.0) on sustainability as there is still a paucity of literature on the implementation of the practices in the healthcare sector. Notably, the growing challenges within service organizations have motivated healthcare organizations to upgrade their conventional delivery system to a smart sophisticated system. Thus, this present study makes an attempt to model these practices as integrated with IR 4.0 technologies into achieving sustainability in the healthcare industry. In order to fill the void of this gap, this study intends to investigate the joint effects of six sigma and IR 4.0 technologies on sustainable performance of healthcare delivery services. The study confirms the future direction of the public health sector that is recently employing new technologies in its service systems. The data shall be collected from the top management employees, the health practitioners who are working and familiar with the services and operations of the organization and are familiar with the smart tools to expedite services for healthcare. This study extends the current literature on IR 4.0 technologies and six-sigma as enablers of economic, environmental and social sustainability. This study unfolds the significant contribution of operations management practices and how sustainable performance can be enhanced through performance variation and strategic implementation of modern technologies in the healthcare sector.

Keywords Six Sigma Practices - Sustainability - Industrial Revolution 4.0 Technologies
\end{abstract} - Healthcare Industry.

Article history

Received: 30 November 2021

Accepted: 15 February 2022

Published: 1 March 2022 


\section{INTRODUCTION}

The growing healthcare costs and the ageing population are imparting challenges on the safety, reliability, and affordability of basic healthcare with the already constrained budgets in both developing and developed countries, while enhanced service quality, high performance, and improved efficiency are still expected. ${ }^{1}$ With these trending issues, healthcare policymakers and providers advocate for the incorporation of six sigma practices to reduce cost, increase value and eliminate waste as other industries have done. ${ }^{2}$ The human and control factors influence good service quality as a result of the successful incorporation of modern manufacturing equipment, human involvement, and statistical process control. Sustainable performance in the service and manufacturing sectors have gained attention in several research documents and projects by various business practitioners. The practice and theory of sustainable performance have become a critical issue in the dynamic business market within manufacturing practices. In terms of product quality, competitive positioning, customer relationship, environmental management and supply chains management, environmental costs, operational practices, strategic plan and action, material selection, and continuous growth and expansion, many organizations have taken this opportunity to implement sustainable practices.

The competition among manufacturing industries has motivated a lot of organisations to upgrade to smart systems from the conventional manufacturing system. ${ }^{3}$ The manufacturing processes are agile, intelligent, well equipped and more flexible to meet the challenges in global and dynamic markets in smart manufacturing systems. $\mathrm{Kamble}^{4}$ reported that industry 4.0 , also known as intelligent and smart manufacturing, expedites the current manufacturing system towards the improvement of intelligent, open, automated and digital manufacturing platforms for an industrially inclined information application. A manufacturing environment in a value chain equipped with industry 4.0 provides all the information flows and physical processes in real-time to the connected partners. ${ }^{5}$ Kamble added that manufacturing organisations employed Industry 4.0 technologies (IR Tech) to achieve sustainability through improved product quality and work environment, reduced lead time, employee morale, and customised products. ${ }^{6}$ Luthra identified IR Tech as a significant initiative for manufacturing systems to achieve economic, ecological and social sustainability in an emerging economy. ${ }^{7}$

Malaysia as a country, located strategically at the centre of south-eastern Asia provides huge opportunities for international component and product manufacturing organisations to standardize operations and distributions in many industries. In current years, enormous attention has been received on sustainable manufacturing practices as efficient solutions to improve expansion and continuous growth in the manufacturing industries of Malaysia. ${ }^{8}$ Evidence from the Malaysia-German Chamber of Commerce and Industry has shown that international component manufacturers and manufacturing companies have attracted Malaysia to launch their products and meet the demands of the consumers in the country. Nevertheless, there is a need for the Malaysian government to redefine and re-strategize its policy on technology advancement to meet up with foreign product standard entry to ensure that it is consistent in the performance of the local companies and safely compete in the global and regional markets. ${ }^{30}$ Thus, standardized structural and manufacturing practices are urgently needed to enhance and computerize manufacturing activities.

\section{METHODOLOGY}

Asides from the fact that this study is contextualized in an attempt to meet the measures of sustainability and the specificity of best quality service initiatives for the Malaysian healthcare industry, the hybrid of Six Sigma and IR 4.0 are newly introduced to test the model of the research. Items to measure sustainability (economic, social and environmental), six sigma (six sigma structured improvement procedure, six sigma focus on metrics and six sigma role structure) and IR 4.0 technologies are presented below.

\section{Sustainability Dimensions}

Sustainability is measured using social, economic and environmental performance with 20 items, adopted from the study of Brent ${ }^{9}$ and Caiado. ${ }^{10}$ The last three years are designated as the assessment period for the organization. Table 1 presents the items measuring sustainability and their respective coding.

Table 1 Sustainability Coding

\begin{tabular}{lc}
\hline Items & Code \\
\hline & \\
Reduced costs of production & EP01 \\
Improved profits & EP02 \\
Reduced product development costs & EP03 \\
Decreased energy costs & EP04 \\
Reduced inventory costs & EP05
\end{tabular}




\begin{tabular}{ll}
$\begin{array}{l}\text { Reduction in rework and rejection cost } \\
\text { Decrease in the purchase cost or raw material } \\
\text { Decrease in the cost of the waste treatment } \\
\text { Social Sustainability }\end{array}$ & EP06 \\
Improved condition of work & EP08 \\
Improved safety in workplace & SP1 \\
Improved health of the employees & SP2 \\
Improved relations on labour & SP3 \\
Improvement in morale & SP4 \\
Decrease in work pressure & SP5 \\
& SP6 \\
Reduced solid wastes & \\
Reduced liquid wastes & EVP01 \\
Reduced gas emission & EVP02 \\
Reduction in energy wastes & EVP03 \\
Decreased consumption of toxic/hazardous/harmful materials & EVP04 \\
Improved environmental condition of the company & EVP05 \\
\hline Source: Brent' and Labuschagne (2004) ${ }^{9}$ and Caiado et al. $(2018)^{10}$ & EVP06 \\
\hline
\end{tabular}

Six Sigma Dimensions

The study of $\mathrm{Zu}$ and items therein are adopted for measuring Six Sigma constructs. ${ }^{11}$ These constructs are six sigma role structure, six sigma focus on metric and Six Sigma improvement procedures as presented in Table 2.

Table 2 Six sigma Coding

Six Sigma Role Structure
Item
Our company reviews daily the progress of the six sigma projects
Our company encourages the transfer of knowledge across the different departments of the organization
Our company encourages cooperation between departments during six sigma planning projects
Our company does request for the progress report of each departmental project
Our company assigns appropriate project for each personnel
Our company has a structure that supports six sigma such as the yellow belts (YBs), green belts (GBs)
and black belts (BBs)
Meetings are organized between a leader and team members to allow project monitoring
The projects on six sigma are related to the demands of the customers/clients
The improvement team is aware of the requirement of the clients
The head of each department reviews the complaint and demands of the clients before creating projects
for six sigma

Six Sigma Structured Improvement Procedure

Our firm provides a regular training schedule on Six Sigma

Black Belts (BBs) and Green Belts (GBs) are assigned to decide on six sigma projects

Black Belts (BBs) and Green Belts (GBs) analyze the problems related to the six sigma projects

The workloads are adjusted to enable time for training and education of six sigma projects

Software and materials are provided for six sigma projects

Six Sigma Focus on Metrics

The results from the projects are considered in career performance

The outcomes of the six sigma projects affect the yearly increase of salary and bonuses at the end of the year

There is a reduction in waste generation in our firm with the implementation of the six sigma practice

There are increased sales in our company with the implementation of six sigma practice

There is an increase in investment return in our company with the implementation of six sigma practice A competitive advantage is created for our company with the implementation of six sigma practice

There are savings in the costs of production with the implementation of the six sigma practice

The defect in production is zero
Code

SSR1

SSR2

SSR4

SSR5

SSR6

SSR7

SSR8

SSR9

SSR10

SSS2

SSS3

SSS4

SSS5

SSF1

SSF2

SSF3

SSF4

SSF5

SSF6 
International Journal of Public Health Research Vol 12 No 1 2022, pp (1528-1535)

Industrial Revolution 4.0 Technologies Dimensions Most of the organizations are yet to explore the sophisticated features of IR 4.0 technologies; therefore, they are uncertain about what benefits of IR 4.0 Technologies would be in the future. ${ }^{12}$ The IR 4.0 technologies adoption in service industries is still at infant stage but slowly gathering momentum. ${ }^{6}$ Therefore, the degree of implementation of IR 4.0 Technologies are aimed to be measured by items but not the successful level of its implementation. Table 3 presents the measuring items for IR 4.0 Technologies as adopted from the study of Kamble. ${ }^{13}$

Table 3 Industrial revolution 4.0 technologies coding

\begin{tabular}{lc}
\hline Items & Code \\
\hline Our company is planning to implement cloud computing & IR1 \\
Our company is planning to implement big data analytics & IR2 \\
Our company is planning to implement internet of things & IR3 \\
Our company is planning to implement additive manufacturing & IR4 \\
Our company is planning to implement a robotic system & IR5 \\
Our company is planning to implement augmented reality & IR6 \\
\hline Source: Kamble et al. $(2018)^{13}$ &
\end{tabular}

\section{DISCUSSION}

Sustainability in Healthcare

Sustainability is achieved in business when a firm or an organization builds continuous values for its shareholders and stakeholders while abiding by environmental regulations. The sustainable performance value of a firm has a few essential parts which are: making the shareholders and customers happy and more importantly, performing well for the society and environment. ${ }^{14}$ The sustainable performance comprises practices that socially facilitate the useful life of an organization, promoting the capacity to renew and maintain the viability of the ecosystem, provide for the living beings and promote the ability of a society to sustain itself in solving the major crisis and maintain decent welfare, personal freedom and participation for human present and future generation. Furthermore, sustainable performance is a product of executing transactions and business towards sustainable enterprise which are made by creating constructive and innovative corporate culture. ${ }^{14}$ Sustainable six sigma practices philosophy appear to have the potential to improve healthcare performance significantly as it has been successfully adopted in many industries but may have nuances that make this industry-specific transformation more challenging and thus pose a threat to sustainability. ${ }^{2}$

Moreover, sustainability in services and manufacturing organizations has attracted significant attention from various research projects and business practitioners in the world. The practices and theories of sustainability have become a crucial issue within the dynamic business development of manufacturing. The integration of IR 4.0 and six- sigma provides a lucratively cost- saving advantage in a critical situation. However, there are still scanty researches that considered the relationships between IR 4.0, six-sigma and sustainability. ${ }^{12}$ There is a lack of awareness on how IR 4.0 Tech enables and facilitates successful application and integration of IR 4.0 and six-sigma to influence sustainability. ${ }^{15}$ As there is no study yet that investigate empirically the relationship between IR 4.0, six-sigma and sustainability performance specifically in the healthcare industry, the current study is undertaken to fill the gap. This study draws on the emerging research on IR 4.0, six-sigma and sustainability performance to develop and validate a model that examines the relationships between the factors.

There are three categories of sustainable performance which includes social, environmental and economic sustainable performance. Sustainable development strategies as confirmed by the European Commission emphasized the significance of economic growth, environmental protection and social cohesion to work together. ${ }^{16}$ The sustainable performance comprises activities that socially extend the useful life of an organization, enhancing the capacity to renew and sustain the viability of the biosphere, maintain decent welfare, self-sustenance of a society, safeguard all the living species and solving its main problems, personal freedom, and participation for current and future human generation.

\section{Six Sigma in Healthcare}

In the 1980 s, Motorola created six sigma as a way to minimize variations and errors in the process of product creation. Antony ${ }^{17}$ reported that the importance of statistical method and data analysis 
technique is highlighted by six sigma to develop optimal business processes such that $99 \%$ efficiency rate is achieved and variability among outputs is minimized. Specifically, integration of output criteria (performance metrics), structured procedures and individual specialists is utilized by the six sigma processes to achieve the goals of reducing errors and variations. The fundamental phases to the six-sigma paradigm are: ${ }^{18}$ define, measure, analyse, improve and control (DMAIC). The specialists identify the potential problems, the expected goals and relevant factors of the six sigma initiatives; the rest of the DMAIC phases is provided by this. The measure phase starts with the data collection to understand the present quality and the output procedure having defined the scope of the problem.

The present highly and rapidly changing market has placed many organizations under pressure to adopt sustainable practices in terms of maintaining an equilibrium of social, economic and environmental performance. ${ }^{19}$ In this vein, the approach of six sigma manufacturing combines the practices that focus on the demand of customers and reduce environmental adverse impact has gained popularity. However, the six sigma practices are still new, lacking clear structured definitions and evidence of successful cases in the industry. Sixsigma is adopted by the organization as an effective tool and problem-solving approach spearheaded by specialists in process improvements, such as the Green Belts (GB) and Black Belts (BB). The sixsigma focuses more on reducing errors in a critical process that can lead to low quality in the eyes of the consumers. The principles under the operations of six-sigma are set to create robust products, services and processes, improve the process average and minimise variations in processes. Six-sigma is an organized, parallel-mesostructure to reduce variation in organizational processes by using improvement specialists, a structured method, and performance metrics to achieve strategic objectives. This definition of six-sigma is the most comprehensive definition to date as it contains both the "what" and "how".

In six sigma, the phase of "analysis" attempts to understand the procedures, processes and practices needed to get the results having understood the results of the processes. The phase of "Improve" having identified the root cause introduces the changes to the processes and/or procedures to address the root cause thereby minimizing the errors and variability in the outputs and achieving a $99 \%$ efficiency rate. The plans and policies are outlined in the control phase to ensure that the improvements in the past stages are moved forward. ${ }^{18}$. Each phase of six sigma most importantly uses statistical techniques to guide the next step and conclusions. This study suggests that six sigma practices and IR 4.0 technologies should be effectively incorporated into the system of the healthcare industry of Malaysia to meet the high demand for service quality. The policymakers and managers of the industry should pay attention to restrategize the policies, structures, and practices to align them with the technological advancements.

Industrial Revolution 4.0 Technologies for Healthcare

Malaysia is considered as one of the countries keeping abreast with the emergency of industrial revolution 4.0. "The success of (ride-sharing and ehailing app) Grab and a home-grown service is an example of the dependence on internet technology for advancement. Malaysians are ready to become a player and mobiliser of this new revolution" said Dr Sawal Hamid, a Senior Lecturer from the Department of Electrical, Electronics and System Engineering, Universiti Kebangsaan Malaysia. ${ }^{20}$ Thus, Malaysia is on its way to becoming an internationally renowned manufacturing country if access to the latest industrial technologies is made easier through the adoption of modern manufacturing practices. The historical background of industrial revolution 4.0 in the last two centuries unfolds a dynamic change to automation (e.g., automated production) and information technology from the power sources, and then connectivity. The industrial revolution revolves around three resources: process, technology and people with each of these initiating a circular pattern of mutual effect and driving the change as shown in Figure 1.

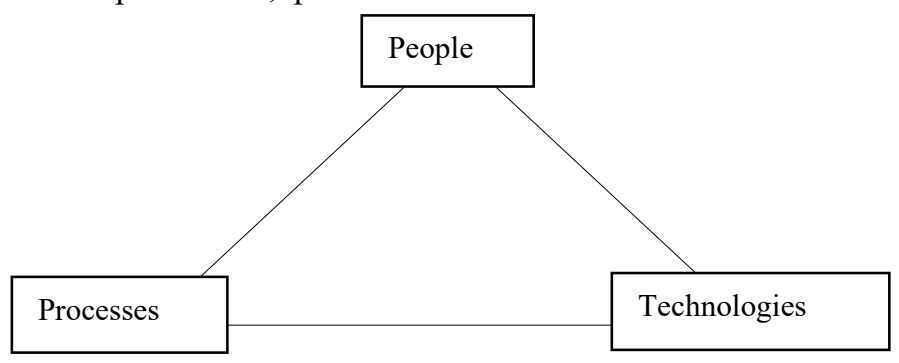

Figure 1 Three Pillars of Industrial Revolution

In the last 30 years, the history of the industrial revolution highlights a shift in power from power sources to automated production, information technology and connectivity. Notably, the industrial 
revolution revolves around three main categories: technologies, processes and people with one of these driving the change and initiating a circular pattern of mutual influence. Industrial Revolution 4.0 is the digital manufacturing system provided by the successful incorporation of information technologies, techniques and production processes. ${ }^{21}$ The main objective of Industrial Revolution 4.0 (IR 4.0) is to improve the efficiency and responsiveness of the manufacturing system. The IR 4.0 technologies operating on the concepts of vertical and horizontal integration of manufacturing systems are influenced by real-time data interchange between many partners in a manufacturing value chain ${ }^{22}$. Additive manufacturing (AM), the internet of things (IoT), robotic systems (RS), big data analytics (BDA), augmented reality (AR), cloud computing (CC) and cyber-physical system (CPS) are identified as the significant Industrial revolution 4.0 technologies that promote process integration, leading to sustainable performance. ${ }^{4}$ From the perspective of social measures, Industrial revolution 4.0 technologies provide abundant opportunities to adapt to new technologies by the employees thereby increasing their motivation and morale. ${ }^{23}$ Therefore, Industrial revolution 4.0 technologies provide safe working conditions and improved work environments for the employees. ${ }^{24}$

A massive amount of data collection, analysis, sharing and storage technologies are generated by Industrial Revolution 4.0 technologies enabled production systems. The BDA for example enhances competitive advantage and business performance sustainability. In addition, BDA is extensively used by manufacturing organizations and they are required to improve the capability of the BDA to explore the benefits of virtual manufacturing system..$^{25}$ Nonetheless, implementing Industrial revolution 4.0 technologies is not devoid of limitations. Carvalho ${ }^{26}$ posit that it is a major barrier as the human controls the adjustment goals and implementation process even though Industrial revolution 4.0 technologies can adjust quickly to the manufacturing environment. Nevertheless, the past studies predicted that Industrial revolution 4.0 technologies would contribute to the objectives of organizational sustainability. A review revealed that six sigma is integrated with IR 4.0 Tech will have a great impact in the healthcare manufacturing and service industry and it is worthwhile to be explored specifically in Malaysia. ${ }^{27}$

\section{CONCLUSION}

Modern organizations are continuously seeking new methods to perform their activities, remain competitive and improve their performance. Continuous improvement initiatives such as the six sigma help organizations to reach a high level of performance, remain competitive and make quick or cohesive process changes by incorporating operations processes. ${ }^{29}$ These practices coupled with IR 4.0 technologies focus on creating more value for the customers by removing waste activities and adding products and services. Similarly, the hybrid six sigma and IR 4.0 technologies have synergized the strength of both distinctive practices to increase the performance of the organization through customer satisfaction while improving the triple bottle line result. Moreover, researchers have shown that integrating IR 4.0 technologies into six sigma are among the least adopted practices by the organization as many manufacturing companies are still in an infant stage of smart system. The integration of IR 4.0 from the advancement of several technologies is viewed to promote economic growth and enable a greener future which are the constituents of Sustainable Development Goals (SDG). ${ }^{28}$

Understandably, these practices require financial resources which pose constraints especially for low margin organizations that are seeking constantly ways to minimize costs and rely on statistical knowledge. Notably, the healthcare industry is one of the main generators of income and employment worldwide. The sector has significantly grown and has affected the policies on the national economy and development to change to a wider system of institutionalised strategies and value creation. This study shall support managers and policymakers in the healthcare industry to devise the best quality management to achieve the best performance. Since the interest of this study is to capture the opinions of the healthcare employees both in the services and operations of the Malaysian healthcare industry, this is undoubtedly justified. This implies that responses are from the perception of individuals on the reality of the work environment and its distinctiveness. Therefore, the relatively complex advancement in these distinctive integrated systems has called for empirical modelling to purposely restructure the current and future objectives of the sector.

\section{REFERENCE}

1. Deblois S, Lepanto L. Lean and Six Sigma in acute care: a systematic review of reviews. International Journal of Health Care Quality Assurance. 2016; 29(2):192208.4. doi: 10.1108/ijhcqa-05-2014-0058.

2. Hallam CRA, Contreras C. Lean healthcare: scale, scope and sustainability. International Journal of Health Care Quality Assurance. 2018; 31(7):684-96. doi: 10.1108/ijhcqa-02-2017-0023.

3. Zhong RY, Xu X, Klotz E, Newman ST. Intelligent Manufacturing in the Context of Industry 4.0: A Review. Engineering [Internet]. Elsevier BV. 2017 Oct; 3(5):616-30. Available from: 
http://dx.doi.org/10.1016/j.eng.2017.05.01 5.

4. Kamble SS, Gunasekaran A, Sharma R. Analysis of the driving and dependence power of barriers to adopt industry 4.0 in Indian manufacturing industry. Computers in Industry. 2018; 101:107-19. doi:10.1016/j.compind.2018.06.004.

5. Vaidya S, Ambad P, Bhosle S. Industry 4.0 - A Glimpse. Procedia Manufacturing [Internet]. Elsevier BV. 2018; 20:233-8. Available from: http://dx.doi.org/10.1016/j.promfg.2018.0 2.034.

6. Kamble SS, Gunasekaran A, Gawankar SA. Sustainable Industry 4.0 framework: A systematic literature review identifying the current trends and future perspectives. Process Safety and Environmental Protection. 2018; 117:408-25. doi:10.1016/j.psep.2018.05.009.

7. Luthra S, Mangla SK. Evaluating challenges to Industry 4.0 initiatives for supply chain sustainability in emerging economies. Process Safety and Environmental Protection [Internet]. Elsevier BV. 2018 Jul; 117:168-79. Available from: http://dx.doi.org/10.1016/j.psep.2018.04.0 18.

8. Habidin NF, Zubir AFM, Fuzi NM, Latip NAM, Azman MNA. Sustainable manufacturing practices in Malaysian automotive industry: confirmatory factor analysis. Journal of Global Entrepreneurship Research [Internet]. Springer Science and Business Media LLC. 2015 Jul 24; 5(1). Available from: http://dx.doi.org/10.1186/s40497-0150033-8.

9. Brent AC, Labuschagne C. Sustainable Life Cycle Management: Indicators to assess the sustainability of engineering projects and technologies. In 2004 IEEE International Engineering Management Conference (IEEE Cat. No. 04CH37574) 2004 (Vol. 1, pp. 99-103). IEEE. doi:10.1109/iemc.2004.1407084.

10. Caiado RG, Quelhas OL, Nascimento DL, Anholon R, Leal Filho W. Measurement of sustainability performance in Brazilian organizations. International Journal of Sustainable Development \& World Ecology. 2018; 25(4):312-26.

11. $\mathrm{Zu} \mathrm{X}$, Fredendall LD, Douglas TJ. The evolving theory of quality management: the role of Six Sigma. Journal of operations Management. 2008; 26(5):630-50. doi:10.1016/j.jom.2008.02.001.
12. Tortorella GL, Fettermann D. Implementation of Industry 4.0 and lean production in Brazilian manufacturing companies. International Journal of Production Research. 2018; 56(8):297587. doi:10.1080/00207543.2017.1391420.

13. Kamble SS, Gunasekaran A, Gawankar SA. Achieving sustainable performance in a data-driven agriculture supply chain: A review for research and applications. International Journal of Production Economics. 2020; 219:179-94. doi:10.1016/j.ijpe.2019.05.022.

14. Hassan MG, Akanmu MD, Yusoff RZ. Technological integration and sustainable performance in manufacturing firms. Industrial Engineering. 2018; 9(8). doi:10.14716/ijtech.v9i8.2747.

15. Buer S-V, Strandhagen JO, Chan FTS. The link between Industry 4.0 and lean manufacturing: mapping current research and establishing a research agenda. International Journal of Production Research [Internet]. Informa UK Limited; 2018 Mar 2; 56(8):2924-40. Available from:

http://dx.doi.org/10.1080/00207543.2018. 1442945.

16. Pei YL, Amekudzi AA, Meyer MD, Barrella EM, Ross CL. Performance measurement frameworks and development of effective sustainable transport strategies and indicators. Transportation Research Record. 2010; 2163(1):73-80. doi: 10.3141/2163-08.

17. Antony J, Snee R, Hoerl R. Lean Six Sigma: yesterday, today and tomorrow. International Journal of Quality \& Reliability Management. 2017. Doi: 10.1108/ijqrm-03-2016-0035.

18. Gupta S, Modgil S, Gunasekaran A. Big data in lean six sigma: a review and further research directions. International Journal of Production Research. 2020; 58(3): 947-69. doi:10.1080/00207543.2019.1598599.

19. Abualfaraa W, Salonitis K, Al-Ashaab A, Ala'raj M. Lean-Green Manufacturing Practices and Their Link to Sustainability. MDPI AG, 2019 Nov 17. Available from: http://dx.doi.org/10.20944/preprints20191 1.0197.v1.

20. The Sun Daily. Malaysia must keep up with Revolution 4.0. 2018. Available from: https://www.thesundaily.my/local/malaysi a-must-keep-up-with-revolution-4-0CI309026.

21. Ahuett-Garza H, Kurfess T. A brief discussion on the trends of habilitating technologies for Industry 4.0 and Smart manufacturing. Manufacturing Letters. 
2018;

15:60-3.

doi:10.1016/j.mfglet.2018.02.011.

22. Fatorachian H, Kazemi H. A critical investigation of Industry 4.0 in manufacturing: theoretical operationalisation framework. Production Planning \& Control. 2018; 29(8):633-44. doi:10.1080/09537287.2018.1424960.

23. Peukert B, Benecke S, Clavell J, Neugebauer S, Nissen NF, Uhlmann E, Lang KD, Finkbeiner M. Addressing sustainability and flexibility in manufacturing via smart modular machine tool frames to support sustainable value creation. Procedia CIRP. 2015; 29:514-9.

24. Kamble S, Gunasekaran A, Dhone NC. Industry 4.0 and lean manufacturing practices for sustainable organisational performance in Indian manufacturing companies. International Journal of Production Research. 2020; 58(5):131937. doi:10.1080/00207543.2019.1630772.

25. Moyne J, Iskandar J. Big Data Analytics for Smart Manufacturing: Case Studies in Semiconductor Manufacturing. Processes [Internet]. MDPI AG; 2017 Jul 12; 5(3):39. Available from: http://dx.doi.org/10.3390/pr5030039.

26. Carvalho N, Chaim O, Cazarini E, Gerolamo M. Manufacturing in the fourth industrial revolution: A positive prospect in Sustainable Manufacturing. Procedia
Manufacturing [Internet]. Elsevier BV; 2018; 21:671-8. Available from: http://dx.doi.org/10.1016/j.promfg.2018.0 2.170.

27. Doh SW, Deschamps F, Pinheiro de Lima E. Systems integration in the lean manufacturing systems value chain to meet industry 4.0 requirements. In Transdisciplinary Engineering: Crossing Boundaries. 2016 (pp. 642-650). IOS Press.

28. Mabkhot MM, Ferreira P, Maffei A, Podržaj P, Mądziel M, Antonelli D, Lanzetta M, Barata J, Boffa E, Finžgar M, Paśko Ł. Mapping Industry 4.0 Enabling Technologies into United Nations Sustainability Development Goals. Sustainability. 2021; 13(5):2560.

29. Akanmu D, Nordin N. Integration of IR 4.0 into Six Sigma for Sustainability in Malaysia Manufacturing Industry. Jurnal Intelek. 2022; 17(1):30-42.

30. Akanmu MD, Bahaudin AY, Jamaludin R. A partial least square structural equation modelling preliminary analysis on total quality management elements and environmental regulation and policy influencing organisational performance in the food and beverage companies of Malaysia. International Journal of Productivity and Quality Management. 2017; 22(1):60-81. 